\title{
Green tea catechins for chemoprevention of prostate cancer in patients with histologically-proven HG-PIN or ASAP. Concise review and meta-analysis
}

\author{
Gianpaolo Perletti ${ }^{1,2}$, Vittorio Magri ${ }^{3},{\text { Anne } \text { Vral }^{2}, \text { Konstantinos Stamatiou }^{4} \text {, Alberto Trinchieri }}^{5}$ \\ ${ }^{1}$ Department of Biotechnology and Life Sciences, Section of Medical and Surgical Sciences, University of Insubria, Varese, Italy; \\ ${ }^{2}$ Department of Human Structure and Repair, Faculty of Medicine and Medical Sciences, Ghent University, Ghent, Belgium; \\ ${ }^{3}$ ASST Nord Milano, Milan, Italy; \\ ${ }^{4}$ Department of Urology, Tzaneio Hospital, Piraeus, Greece; \\ ${ }^{5}$ Urology Unit, Manzoni Hospital, Lecco, Italy.
}

\begin{abstract}
Summary A focused, single outcome meta-analysis on the protective role of extracts of green tea catechins against prostate cancer. Randomized, placebo-controlled studies enrolling patients with a histologically confirmed diagnosis of high-grade Prostate Intraepithelial Neoplasia or Atypical Small Acinar proliferation but no prostate cancer were included. Meta-analysis for binary data was performed using Mantel-Haenszel statistics, using a random-effects model. Heterogeneity was investigated by calculating the $\mathrm{I}^{2}$.

Four studies matched the inclusion criteria for the review. The pooled population was 223 patients; 114 and 109 patients were randomized to catechin and placebo groups, respectively. Nine cases of prstate cancer occurred in the catechin arm (7.9\%), and 24 cases were reported in the placebo arm (22\%). Pooled analysis resulted in a significant reduction of cancer risk in favor of the catechin arm (risk-ratio $=0.41 ; 95 \%$ CI: 0.19$0.86 ; I^{2}=0$ ).

In conclusion, our data suggest that the intake of concentrated green tea catechin preparations may confer a significant protective effect to carriers of early neoplastic lesions in the prostate. The quality of the evidence is moderate, and additional, largescale studies are warranted to substantiate these preliminary findings.
\end{abstract}

KEY WORDS: Green tea; Prostate cancer; Prostate; Polyphenols; Catechins; Epigallocatechin-3-gallate.

Submitted 8 July 2019; Accepted 22 July 2019

\section{INTRODUCTION}

In vitro, in vivo and epidemiological studies suggest that the high polyphenol content of green tea may confer to this beverage a protective effect against prostate cancer (PCa) (1-5).

From year 2006, randomized clinical trials have been performed, focusing on the role of green tea catechins (mainly epigallocatechin-3-gallate) on the prevention or retardation of the onset of prostate cancer.

In 2017, a meta-analysis by Cui et al., based on two randomized, double-blind, placebo-controlled phase II trials, resulted in a slightly significant protective effect of concentrated green tea catechin preparations, in patients with histologically proven suspicious lesions (high-grade prostatic intraepithelial neoplasia [HG-PIN], atypical smallacinar proliferation [ASAP]) (6). In the same year, Guo et al. performed a similar meta-analysis by adding a third updated study to the pooled trials. Also in this case, catechins showed a significant protective effect against prostate cancer (5). The aim of this review and metaanalysis was to search for additional phase II studies published in the literature, and, if possible, to attempt meta-analysis of the global data published so far.

\section{MATERIALS AND MEtHOdS}

A search of the PubMed/Medline and Embase databases of publications in English, indexed up to June 7th, 2019 was performed, using the following terms: prostate, prostate cancer, *carcinoma, green tea, tea, catechin*, *gallate, ECGC.

The single outcome for this review was the incidence/prevalence of prostate cancer in included patients.

Inclusion criteria

(i) patients with histologically-proven HG-PIN and/or ASAP of any age, included in randomized, placebo-controlled clinical trials; (ii) the active treatment arm received a concentrated preparation of green tea catechins; (iii) placebo-controlled studies.

\section{Exclusion criteria}

(i) non-randomized trials; (ii) a diagnosis of prostate cancer; (iii) any combination therapy (catechins combined with other drugs or supplements, with surgical procedures, with radiotherapy, etc.).

Risk of bias analysis was performed by two investigators using the Cochrane risk of bias tool (7). The MetaEssentials software was used for publication bias analysis (8). Meta-analysis for binary data was performed using Mantel-Haenszel statistics with the Cochrane Review Manager 5.3 software.

We planned to use a random-effects model, and to attempt confirmatory analysis with a fixed-effects model in case of low heterogeneity. Heterogeneity was investigated by calculating the $\mathrm{I}^{2}$. 
Figure 1.

Pooled analysis of four randomized, placebo-controlled studies investigating the protective effect of green tea catechins on the incidence of prostate cancer. The number of subjects allocated to treatment arms, the number of cases of PCa, the risk-ratios, the 95\% confidence intervals, the $Z$ value for the overall effect, the significance of the pooled comparisons, and heterogeneity data $\left(\mathrm{Chi}^{2}, \mathrm{l}^{2}\right)$, are presented. Data to the left of the vertical no-effect line of the forest plot represent decreased risk for prostate cancer. The diamond represents the overall effect size extending to the limits of the $95 \%$ confidence interval of the pooled risk-ratio.

The risk of bias analysis for each included study, with explanatory footnotes, is also shown.

\begin{tabular}{|c|c|c|c|c|c|c|c|c|c|}
\hline \multirow[b]{2}{*}{ Study or Subgroup } & \multicolumn{2}{|c|}{ Catechins } & \multicolumn{2}{|c|}{ Placebo } & \multirow[b]{2}{*}{ Weight } & Risk Ratio & \multirow{2}{*}{\multicolumn{2}{|c|}{$\begin{array}{l}\text { Risk Ratio } \\
\mathrm{M}-\mathrm{H}, \text { Random, } 95 \% \mathrm{Cl}\end{array}$}} & Risk of Bias \\
\hline & Events & Total & Events & Total & & $\mathrm{M}-\mathrm{H}$, Random, $95 \% \mathrm{Cl}$ & & & A B CDEFG \\
\hline Bettuzzi 2006 & 1 & 30 & 9 & 30 & $13.8 \%$ & $0.11[0.01,0.82]$ & 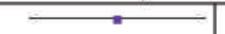 & & ??†? ?४? \\
\hline Brausi 2008 & 1 & 13 & 2 & 9 & $11.0 \%$ & $0.35[0.04,3.27]$ & & & ? ?९?๑९? \\
\hline Micali 2017 & 2 & 22 & 4 & 22 & $21.9 \%$ & $0.50[0.10,2.45]$ & 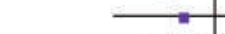 & - & $\hookrightarrow ? \odot ? \odot ? ?$ \\
\hline Kumar 2015 & 5 & 49 & 9 & 48 & $53.4 \%$ & $0.54[0.20,1.51]$ & - & - & ๑? ४९९? ? \\
\hline Total $(95 \% \mathrm{CI})$ & & 114 & & 109 & $100.0 \%$ & $0.41[0.19,0.86]$ & & & \\
\hline \multicolumn{7}{|c|}{$\begin{array}{l}\text { Total events } \\
\text { Heterogeneity: } \mathrm{Tau}^{2}=0.00 ; \mathrm{Chi}^{2}=2.13, \mathrm{df}=3(\mathrm{P}=0.55) ; \mathrm{I}^{2}=0 \%\end{array}$} & & & \\
\hline \multicolumn{7}{|c|}{$\begin{array}{l}\text { Heterogeneity: } \text { Tau }^{2}=0.00 ; \mathrm{Chi}^{2}=2.13, \mathrm{df}=3(\mathrm{P}=0.55) ; \mathrm{I}^{2}=0 \% \\
\text { Test for overall effect: } \mathrm{Z}=2.36(\mathrm{P}=0.02)\end{array}$} & $\begin{array}{lll}0.01 & 0.1 & 1 \\
\text { Favours catechins }\end{array}$ & $\underset{10}{10} 100$ & \\
\hline \multicolumn{10}{|l|}{ Risk of bias legend } \\
\hline \multicolumn{10}{|c|}{$\begin{array}{l}\text { KISk of blas legend } \\
\text { (A) Random sequence generation (selection bias) }\end{array}$} \\
\hline \multicolumn{10}{|c|}{ (B) Allocation concealment (selection bias) } \\
\hline \multirow{2}{*}{\multicolumn{10}{|c|}{ (C) Blinding of participants and personnel (performance bias) }} \\
\hline & & & & & & & & & \\
\hline \multicolumn{10}{|c|}{ (E) Incomplete outcome data (attrition bias) } \\
\hline \multicolumn{10}{|c|}{ (F) Selective reporting (reporting bias) } \\
\hline (G) Other bias & & & & & & & & & \\
\hline
\end{tabular}

\section{RESULTS}

Literature database search retrieved 3230 deduplicated records. Title and abstract were screened by two investigators, who selected 7 records for further full-text reading, with no disagreements. Three articles were agreed to be excluded for the following reasons: (i) catechins not administered as single-agents, but combined with other supplements (9), (ii) a feasibility study, without cancer incidence as an outcome (10), (iii) a study performed before prostatectomy in men diagnosed with PCa (11).

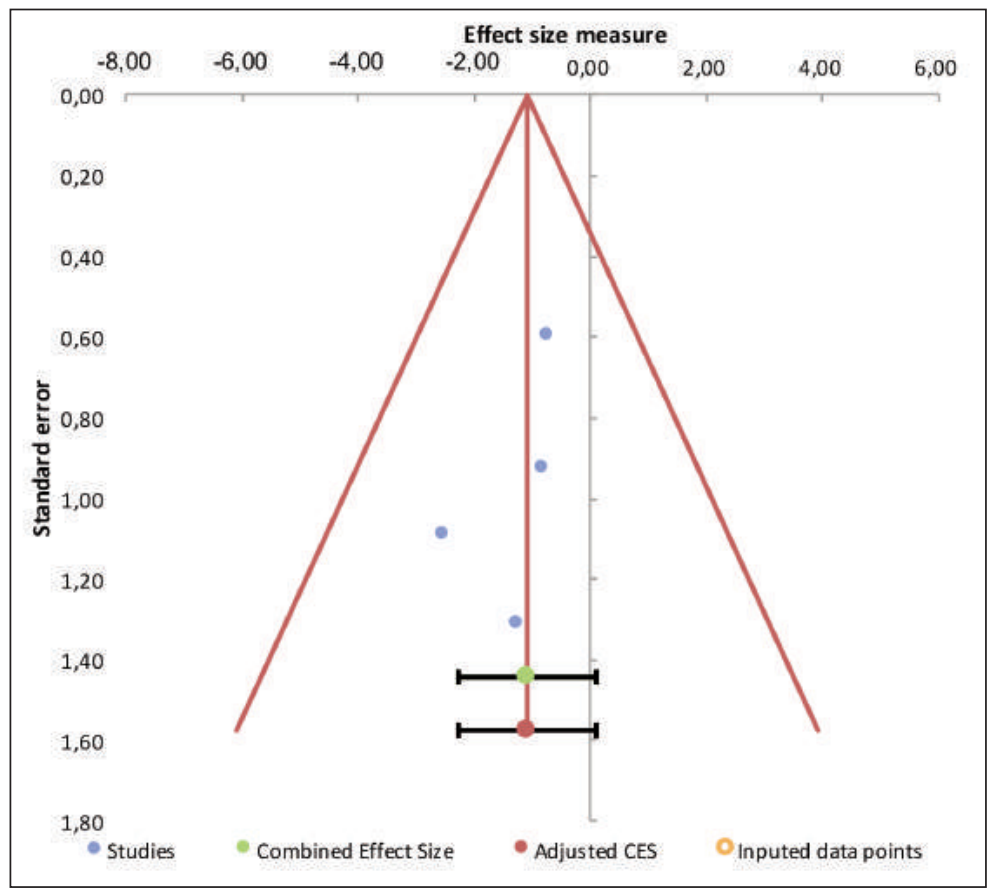

Four articles were finally selected for risk of bias assessment and meta-analysis (12-15).

Two and three of these studies were included in the metaanalyses of Cui et al. (6) and Guo et al. (5), respectively. Thus, the present meta-analysis updates their results by addition of two or one extra trial(s), respectively.

Figure 1 shows the forest plot for the present metaanalysis.

The total population is 223 patients; 114 and 109 patients were randomized to catechin and placebo groups, respectively. Nine cases of $\mathrm{PCa}$ occurred in the catechin arm (7.9\%), and 24 cases were reported in the placebo arm (22\%). Although 3 out of 4 studies showed non-significant risk-ratios (12, 13, 15), pooled analysis resulted in a significant reduction of $\mathrm{PCa}$ risk in favor of the catechin $\operatorname{arm}(\mathrm{RR}=0.41 ; 95 \% \mathrm{CI}:$ 0.19-0.86; $\mathrm{p}=0.02$ ), thus confirming and supporting the significant data shown by Cui et al. $(\mathrm{RR}=$ 0.39; 95\% CI: 0.16-0.97) and by Guo et al. $(\mathrm{RR}=0.38 ; 95 \% \mathrm{CI}: 0.16-0.86)(5,6)$.

Calculation of the odds ratio for the same studies also resulted in a significant associa-

\section{Figure 2.}

Funnel plot for publication bias analysis. We found no evidence of publication bias; the combined effect size (CES, green) and the adjusted estimate of the combined effect size (red) are identical, as no imputation of missing studies was made by the "trim-and-fill" method. In this plot the effect size is expressed as the natural logarithm of the odds ratio. 
Table 1.

Green tea catechins for the prevention of prostate cancer.

\begin{tabular}{|c|c|c|c|c|c|c|}
\hline \multicolumn{7}{|c|}{$\begin{array}{l}\text { Patient or population: men with HG-PIN and/or ASAP } \\
\text { Intervention: green tea catechin preparations } \\
\text { Comparison: placebo }\end{array}$} \\
\hline Outcomes & $\begin{array}{l}\text { Illustrative com } \\
\text { Assumed risk } \\
\text { Placebo }\end{array}$ & $\begin{array}{l}\text { tive risks* } \\
\text { Corresponding risk }(95 \% \mathrm{Cl}) \\
\text { Catechins }\end{array}$ & Relative effect (95\% Cl) & No of Participants (studies) & Quality of the evidence (GRADE) & Comments \\
\hline $\begin{array}{l}\text { Prostate cancer } \\
\text { occurrence }\end{array}$ & 220 per 1000 & $\begin{array}{l}90 \text { per } 1000 \\
\text { (42 to } 189 \text { ) }\end{array}$ & $\begin{array}{l}\text { Risk-ratio: } 0.41 \\
(0.19 \text { to } 0.86)\end{array}$ & $\begin{array}{l}223 \\
\text { (5 studies) }\end{array}$ & $\begin{array}{l}\oplus \oplus \oplus \odot \ominus \\
\text { Moderate }\end{array}$ & $\begin{array}{l}\text { @High risk of attrition } \\
\text { bias in two studies and small number } \\
\text { of participants; } \\
\text { @Low heterogeneity; } \\
\text { @Low probability of publication bias }\end{array}$ \\
\hline \multicolumn{7}{|c|}{$\begin{array}{l}\text { *The assumed risk is based on the occurrence of cases of prostate cancer in the placebo population. The corresponding risk (and its 95\% confidence interval) is based on the assumed risk in the comparison group } \\
\text { and the relative effect of the intervention (and its } 95 \% \text { CI). } \\
\text { CI: Confidence interval; RR: Risk Ratio; OR: odds ratio }\end{array}$} \\
\hline \multicolumn{7}{|c|}{$\begin{array}{l}\text { GRADE Working Group grades of evidence } \\
\text { High quality: Further research is very unlikely to change our confidence in the estimate of effect. } \\
\text { Moderate quality: Further research is likely to have an important impact on our confidence in the estimate of effect and may change the estimate. } \\
\text { Low quality: Further research is very likely to have an important impact on our confidence in the estimate of effect and is likely to change the estimate. } \\
\text { Very low quality: We are very uncertain about the estimate. }\end{array}$} \\
\hline
\end{tabular}

tion between catechin consumption and a lesser prevalence of PCa $(\mathrm{OR}=0.34 ; 95 \% \mathrm{CI}: 0.15-0.80 ; \mathrm{p}=0.01)$. Since the present meta-analysis was devoid of heterogeneity $\left(\mathrm{I}^{2}=0\right)$, we re-calculated the risk-ratio using a fixed-effect model.

The significance of the pooled data was confirmed $(\mathrm{RR}=$ 0.36; 95\% CI: 0.17-0.74; $\mathrm{p}=0.006$; $12=0$ ).

The publication bias was found to be non-significant by both Egger's and Begg-Mazumdar's tests $(p=0.36$ and $p$ $=0.17$, respectively), and the "trim-and-fill" method applied to funnel plot analysis did not impute missing studies (Figure 2).

The Cochrane risk of bias tool allowed to assign a high risk of attrition bias to the studies by Kumar et al. and Micali et al. (Figure 1, red symbols); this was due to incomplete outcome data owing to $28 \%$ and $27 \%$ patient dropout rates, respectively.

The remaining items of the Cochrane tool show low or unclear risk of bias (Figure 1, green or yellow symbols respectively).

The overall quality of the evidence is "moderate", as shown in the summary of findings table for the present meta-analysis (GRADE criteria, Table 1).

\section{Conclusions}

In conclusion, our updated meta-analysis suggests that the intake of concentrated green tea catechin preparations may confer a significant protective effect to carriers of early neoplastic lesions in the prostate (HG-PIN, ASAP).

\section{Strengths}

The meta-analysis was devoid of heterogeneity and publication bias; the general quality of the evidence is moderate, according to GRADE criteria.

Limitations: the considerable percentage of dropouts in two studies suggests the presence of attrition bias.

\section{Caveat}

It is known that lesions like HG-PIN may co-exist with frank carcinoma lesions, which may remain undetected in standard bioptic assessments due to their small size or to the low number of cores. This may be a confounder and a source of detection bias in the studies included in this analysis.

\section{ACKNOWLEDGEMENTS}

We thank Louise Beckers (Ghent University, Belgium) for assistance in database search and data extraction.

\section{REFERENCES}

1. Hastak K, Agarwal MK, Mukhtar H, Agarwal ML. Ablation of either 21 or Bax prevents p53-dependent apoptosis induced by green tea polyphenol epigallocatechin-3-gallate. FASEB J. 2005; 19:789-91.

2. Siddiqui IA, Malik A, Adhami VM, et al. Green tea polyphenol EGCG sensitizes human prostate carcinoma LNCaP cells to TRAILmediated apoptosis and synergistically inhibits biomarkers associated with angiogenesis and metastasis. Oncogene. 2008; 27:2055-63.

3. Siddiqui IA, Shukla Y, Adhami VM, et al. Suppression of NFkappaB and its regulated gene products by oral administration of green tea polyphenols in an autochthonous mouse prostate cancer model. Pharm Res. 2008; 25:2135-42.

4. Zheng J, Yang B, Huang T, et al. Green tea and black tea consumption and prostate cancer risk: an exploratory meta-analysis of observational studies. Nutr Cancer. 2011; 63:663-72.

5. Guo Y, Zhi F, Chen P, et al. Green tea and the risk of prostate cancer: A systematic review and meta-analysis. Medicine (Baltimore). 2017; 96:e6426.

6. Cui K, Li X, Du Y, et al. Chemoprevention of prostate cancer in men with high-grade prostatic intraepithelial neoplasia (HGPIN): a systematic review and adjusted indirect treatment comparison. Oncotarget. 2017; 8:36674-36684. 
7. Higgins JP, Altman DG, Gøtzsche PC, et al. Cochrane Bias Methods Group; Cochrane Statistical Methods Group. The Cochrane Collaboration's tool for assessing risk of bias in randomised trials. BMJ. 2011; 343:d5928.

8. Suurmond $R$, van Rhee $H, H a k T$. Introduction, comparison, and validation of Meta-Essentials: A free and simple tool for metaanalysis. Res Synth Methods. 2017; 8:537-553.

9. Gontero P, Marra G, Soria F, et al. A randomized double-blind placebo controlled phase I-II study on clinical and molecular effects of dietary supplements in men with precancerous prostatic lesions. Chemoprevention or "chemopromotion"? Prostate. 2015; 75:1177-86.

10. Lane JA, Er V, Avery KNL, et al. A Phase II Randomized Placebo-controlled Trial of Green Tea Catechins and Lycopene in Men at Increased Risk of Prostate Cancer. Cancer Prev Res (Phila). 2018; 11:687-696.

11. Nguyen MM, Ahmann FR, Nagle RB, et al. Randomized, double-blind, placebo-controlled trial of polyphenon $E$ in prostate can- cer patients before prostatectomy: evaluation of potential chemopreventive activities. Cancer Prev Res (Phila). 2012; 5:290-8.

12. Kumar NB, Pow-Sang J, Egan KM, et al. Randomized, PlaceboControlled Trial of Green Tea Catechins for Prostate Cancer Prevention. Cancer Prev Res (Phila). 2015; 8:879-87.

13. Brausi M, Rizzi F, Bettuzzi S. Chemoprevention of human prostate cancer by green tea catechins: two years later. A follow-up update. Eur Urol. 2008; 54:472-3.

14. Bettuzzi S, Brausi M, Rizzi F, et al. Chemoprevention of human prostate cancer by oral administration of green tea catechins in volunteers with high-grade prostate intraepithelial neoplasia: a preliminary report from a one-year proof-of-principle study. Cancer Res. 2006; 66:1234-40.

15. Micali S, Territo A, Pirola GM, et al. Effect of green tea catechins in patients with high-grade prostatic intraepithelial neoplasia: Results of a short-term double-blind placebo controlled phase II clinical trial. Arch Ital Urol Androl. 2017; 89:197-202.

\section{Correspondence}

Gianpaolo Perletti

gianpaolo.perletti@uninsubria.it

Department of Biotechnology and Life Sciences, Section of Medical and Surgical Sciences, University of Insubria, Varese, Italy Department of Human Structure and Repair, Faculty of Medicine and Medical Sciences, Ghent University, Ghent, Belgium

\section{Vittorio Magri}

vittorio.magri@virgilio.it

ASST Nord Milano, Milan, Italy

Anne Vral

Department of Human Structure and Repair, Faculty of Medicine and Medical Sciences, Ghent University, Ghent, Belgium

Konstantinos Stamatiou

stamatiouk@gmail.com

Department of Urology, Tzaneio Hospital, Piraeus, Greece

Alberto Trinchieri

alberto.trinchieri@gmail.com

Urology Unit, Manzoni Hospital, Lecco, Italy 